\title{
"Estamos en guerra contra un enemigo poderoso, implacable": los discursos de Sebastián Piñera y la revuelta popular en Chile $^{1}$
}

\author{
Federico Navarro ${ }^{* *}$ \\ Carlos Tromben ${ }^{* * *}$
}

\begin{abstract}
Resumen
Desde el análisis crítico del discurso político, se investigaron los 46 discursos oficiales del presidente Sebastián Piñera emitidos el mes previo y posterior a las masivas protestas sociales iniciadas el 18 de octubre de 2019 en Chile. Se utilizaron métodos complementarios asistidos por software para contrastar e interpretar palabras clave, evaluaciones, metáforas y temas, junto con elementos situacionales y sociales. Los hallazgos demuestran un cambio drástico en el discurso presidencial desde el 18 de octubre, cuando pasó de temáticas económicas y medio ambientales internacionales al aval de las fuerzas de seguridad en el ámbito nacional, pero una continuidad en un discurso de la guerra aplicado al espacio público, para culminar en un discurso inclusivo del acuerdo transversal, la nueva Constitución y los derechos sociales.
\end{abstract}

Palabras clave: análisis crítico del discurso, discurso político, colocación léxica, metáfora, métodos complementarios

\section{"We are at war against a powerful, implacable enemy": Sebastián Piñera's discourses and the popular uprising in Chile}

\begin{abstract}
Drawing from critical political discourse analysis, this article aimed to investigate the 46 official speeches by president Sebastián Piñera delivered one month before and after widespread social protests that started on October 18, 2019 in Chile. Using computer-assisted complementary methods, we contrasted and interpreted keywords, evaluations, metaphors, and themes, along with situational and social elements. Our findings demonstrate a dramat-
\end{abstract}

\footnotetext{
Este trabajo forma parte de una línea de investigación que el primer autor desarrolla desde el año 2011 sobre discurso político, así como de una línea de investigación sobre Sebastián Piñera que el segundo autor desarrolla desde 2014. Se agradecen las valiosas sugerencias de Annabelle Lukin, Anna Ivanova y Sara Pérez sobre una versión preliminar de este artículo, si bien cualquier error u omisión es exclusiva responsabilidad de los autores.

*Argentino. Doctor en Lingüística de la Universidad de Valladolid. Académico de la Universidad de O’Higgins, Región de O’Higgins, Chile.navarro@uoh.cl

" Chileno. Licenciado en Economía de la Pontificia Universidad Católica de Valparaíso. Profesor de la Universidad Alberto Hurtado, Región Metropolitana, Chile. ctromben@uah.cl
} 
ic change in presidential speeches since October 18, when they shifted from international economic and environmental issues to the endorsement of security forces at the national level, along with a continuity of a discourse of war directed towards the public space, to culminate in an inclusive discourse on agreement, the new Constitution, and social rights.

Keywords: critical discourse analysis, political discourse, lexical colocation, metaphor, complementary methods

\section{Introducción}

El análisis del discurso político cuenta con al menos cuatro décadas de tradición en Latinoamérica (AAVV, 1986; Munizaga, 1983; Sigal \& Verón, 1985). En los últimos años, han proliferado trabajos sobre el discurso de presidentes y presidentas asociados grosso modo a la izquierda y al progresismo regional, como Eduardo Frei Montalva, Salvador Allende, Raúl Alfonsín, Ricardo Lagos, Michelle Bachelet, Cristina Fernández, Néstor Kirchner, Luiz Inácio Lula da Silva, José Pepe Mujica, Evo Morales o Hugo Chávez (ver volúmenes colectivos Bein, Bonnin, di Stefano, Lauria, \& Pereira, 2018; Narvaja de Arnoux \& Zaccari, 2015; Pérez, 2014). Las investigaciones en general han identificado cualitativamente recursos lingüísticos, a partir de fragmentos textuales que operan como evidencias empíricas, con frecuencia aprovechando contrastes entre series temporales o entre distintos hablantes o discursos, con el fin último de reconocer constructos ideológicos y hacer aportes a la comprensión crítica de fenómenos y procesos sociales e históricos con los que esos discursos e ideologías se vinculan dialécticamente. Sin embargo, es menos frecuente hallar estudios críticos sobre los discursos de los presidentes pertenecientes a la derecha regional, como Mauricio Macri (Slimovich, 2017) o Sebastián Piñera (Guerrero \& Vega, 2014; Ivanova, 2015), si bien esta línea de investigación se ha incrementado últimamente, tanto en Latinoamérica como en otras regiones (e.g., Sclafani, 2018; Wodak, 2015). Además, los estudios de la región no suelen utilizar métodos complementarios que permitan triangular evidencias y comprender el alcance de los hallazgos en corpus amplios.

Sebastián Piñera, un empresario chileno que hizo fortuna gestionando activos financieros, inició su carrera política como senador en la primera elección tras el retorno a la democracia en 1990 (Tromben, 2016). Su primer mandato presidencial coincidió con las protestas estudiantiles del año 2011. El 18 de octubre de 2019, un año y siete meses después de 
comenzar su segundo mandato, se produjo en Chile un estallido social que solo tiene precedentes en las movilizaciones de la década de 1930.

La presente investigación identifica los cambios y continuidades en el discurso del presidente Sebastián Piñera en el marco de las protestas sociales recientes en Chile. Utilizando técnicas cualitativas y cuantitativas y con asistencia de software NVivo Pro 12 y AntConc 3.5.8, se analizan elecciones léxicas, colocaciones, opuestos binarios, palabras clave, evaluaciones, temas discursivos, metáforas, intertextualidad y estrategias discursivas en los 46 discursos, conferencias y entrevistas de Sebastián Piñera durante el mes anterior y posterior a la irrupción de la protesta social en Chile, según información oficial de presidencia de la república. Los hallazgos se vinculan con las construcciones ideológicas que vehiculizan y con los procesos sociales e históricos a los que se dirigen.

Los resultados de este estudio buscan colaborar no solo con el conocimiento científico sobre discurso político, en particular sobre el discurso de la derecha latinoamericana reciente, sino que además brindan evidencias e interpretaciones para profundizar en la comprensión de la coyuntura chilena en una etapa de agitados cambios sociales y políticos con pocos precedentes en el país. Adicionalmente, este artículo ofrece una aproximación novedosa a la temática fundamentada en métodos complementarios, con asistencia de software para análisis textual tanto cualitativo como cuantitativo, así como triangulación y visualizaciones diversas de las evidencias.

\section{Análisis crítico del discurso político}

Los discursos, en tanto construcciones de significado en contexto social, tienen efectos de corto, mediano y largo plazo en dimensiones simbólicas como los conocimientos, las creencias y las identidades de las personas, pero también producen cambios en las prácticas y relaciones sociales, así como en el mundo material (Fairclough, 2003). Estos efectos y consecuencias de los discursos no son mecanicistas, regulares ni completamente predecibles, sino que los discursos establecen relaciones dialécticas con las creencias, las prácticas y el mundo material en contextos sociales e históricos complejos. De esta forma, el lenguaje es considerado un agente central del proceso de construcción de la realidad (Halliday, 2017). Desde una perspectiva crítica, resulta de interés estudiar el rol del discurso en la construcción, modificación o reproducción de ideologías entendidas 
como representaciones, prácticas e identidades que establecen relaciones de poder, dominación y abuso (Fairclough, 2003). Mediante el discurso se negocian e instalan sentidos comunes y valoraciones, se interpretan y visibilizan (o invisibilizan) temas, se construyen identidades y pertenencias, se ponen en escena visiones de la realidad y se ocupan roles y relaciones de poder que tienen efectos simbólicos y materiales concretos, multidireccionales y complejos.

Como parte del discurso en contexto social, el discurso político corresponde al discurso de individuos (políticos, pero también ciudadanos), instituciones y organizaciones, en el modo oral, escrito o multimodal, que participan en procesos y eventos políticos (reuniones de gabinete, campañas electorales, protestas sociales, etc.), y que discuten y definen líneas de acción respecto de ciertas circunstancias y propósitos (van Dijk, 1998). El encuadre institucional del discurso político, algo evidente en el caso de discursos presidenciales o parlamentarios, es su rasgo clave, ya que ese contexto habilita y empodera la agencia de los actores para actuar sobre el mundo e influir en la realidad (Fairclough \& Fairclough, 2012), si bien algunos autores también incluyen como objeto de interés el discurso de la política mundana o cotidiana (Chilton \& Schäffner, 2002). El discurso político no solo busca convencer y persuadir, sino sobre todo imponer sentidos ideológicamente orientados que impactan sobre la sociedad y sus instituciones, porque interpretan su historia, sus relaciones, sus roles y sus identidades, desde una posición que muchas veces es de privilegio, elite y poder institucionalizado. De hecho, a través del discurso se producen acciones sobre la realidad, como declarar una guerra o nombrar una ministra, y esta dimensión ilocucionaria y perlocucionaria del lenguaje es central en el caso del discurso político: comunicar en política es hacer política. En suma, la política y la participación ciudadanas son intrínsecamente discursivas (Chilton \& Schäffner, 2002).

El análisis del discurso político está motivado en un interés crítico por la reproducción y resistencia por medio del discurso a las relaciones hegemónicas y de poder, especialmente en contextos de crisis e inestabilidad. Como propone van Dijk (1998), el análisis del discurso político se ocupa de la inequidad social producto de relaciones de dominación discursiva, y sus hallazgos pueden proporcionar evidencias para comprender ciertos aspectos de los procesos políticos que, de otra manera, podrían permanecer ocultos o negados. En efecto, el análisis 
cobra particular relevancia cuando el discurso político se aleja del contexto "normal" y predecible de su ejercicio (foros internacionales, ceremonias programadas, inauguraciones de obras públicas, etc.) e ingresa en el terreno de la incertidumbre, del riesgo y del desacuerdo (Fairclough \& Fairclough, 2012), es decir, cuando la toma de decisiones y el quehacer se poblematizan en tiempo real. Como plantea Žižek (2009), las crisis sociales e históricas abren el espacio para la disputa discursiva respecto de qué interpretación o narrativa ideológica se haga de ellas, y qué efectos tengan.

En sistemas democráticos presidencialistas como el chileno, calificado también como un presidencialismo reforzado o vigorizado (Bronfman Vargas, 2016), resulta de interés el análisis crítico del discurso de la máxima autoridad de gobierno. En esta posición de enunciación privilegiada y asimétrica de poder, de visibilidad multiplicada en medios de comunicación masiva y cadenas nacionales, el discurso presidencial tiene un impacto simbólico y material privilegiado en las prácticas, acciones y reacciones de las instituciones públicas y de la sociedad en general. Aunque monologal en su enunciación, es profundamente dialógico, ya que incluye interrelaciones con otros discursos y propone y disputa con otros actores, perspectivas y evaluaciones sobre la realidad que impulsan cambios dentro de la dinámica política (Bolívar, 2009).

Entre las evidencias textuales pertinentes para el análisis del discurso político, se incluyen la frecuencia, colocación (palabras o frases con las que tienden a combinarse) y concordancia (contextos textuales de aparición) de elecciones léxicas (cf. Bolívar, 2009). Ciertos elementos léxicos que operan como nodos semánticos correspondientes a constructos ideológicos (Lukin, 2018) pueden utilizarse para identificar temas, conceptualizaciones y valoraciones predominantes. Dentro de los ítems léxicos frecuentes, se destacan las palabras clave, entendidas como aquellas palabras de baja frecuencia en otros discursos, es decir, cuya importancia radica en que su uso relativo en el discurso bajo análisis es mayor que en otros discursos o ámbitos, avalado por pruebas de significancia estadística (McEnery, Xiao, \& Tono, 2006). En el análisis de las elecciones léxicas también es valioso identificar opuestos binarios, ya que el discurso político tiende a preferir el uso de ítems opuestos que colaboran con la construcción de posiciones ideológicas (Chilton, 2004). De la misma forma, las evaluaciones asociadas a ciertos temas pueden arrojar luz sobre la construcción ideológica en el discurso político, en donde es frecuente la polarización evaluativa (van Dijk, 1998). 
Sin embargo, este tipo de análisis cuantitativo de piezas léxicas aisladas o combinadas no basta para comprender el funcionamiento de los discursos y de los constructos ideológicos que manifiestan y promueven, y por eso requiere ser complementado con otros recursos discursivos en contexto y otros métodos de análisis (Lukin, 2018). En particular, resulta de interés para el discurso político el análisis del uso de ciertos temas discursivos (Wodak, 2015; van Dijk, 1998) que condensan los contenidos priorizados en los discursos. A su vez, el análisis del discurso político puede servirse de la identificación de metáforas, entendidas como formas de razonamiento que vinculan un ámbito de sentido con otro (Chilton, 2004). Además, es relevante el estudio de la intertextualidad, es decir, de la forma en que los discursos recuperan y se hacen eco, de forma explícita o implícita, de otros discursos anteriores (Wodak, 2015). Por último, se destaca para el análisis del discurso político la identificación de estrategias discursivas utilizadas con fines de persuasión (Wodak, 2015; van Dijk, 1998).

\section{Metodología}

Según especifica la Tabla 1, el corpus de análisis se construyó a partir de la transcripción de 46 discursos, conferencias y entrevistas orales presidenciales del presidente chileno Sebastián Piñera entre el 18 de septiembre y el 17 de noviembre de 2019, es decir, durante el mes anterior y posterior a la irrupción de la protesta social en Chile (18 de octubre), utilizando los videos y transcripciones oficiales presentes en la web de prensa del gobierno chileno (prensa.presidencia.cl). El análisis se centró en el uso de recursos lingüísticos y, por tanto, no se consideraron aspectos prosódicos (acentos, pausas, entonación, etc.), si bien se abordaron algunos aspectos proxémicos y kinésicos generales, y se aportaron rasgos del contexto social e histórico para interpretar los hallazgos.

Tabla 1. Corpus de análisis discursos presidenciales oficiales de Sebastián Piñera del 18/o9/2019 al 17/11/2019.

\begin{tabular}{|c|c|c|c|}
\hline Corpus & Fecha & N. de discursos & N. de palabras \\
\hline 1 & $18 / 09 / 2019-17 / 10 / 2019$ & 30 & 44096 \\
\hline 2 & $18 / 10 / 2019-17 / 11 / 2019$ & 16 & 17186 \\
TOTAL & $18 / 09 / 2019-17 / 11-2019$ & 46 & 61282 \\
\hline
\end{tabular}

Con asistencia del software NVivo Pro 12 y AntConc 3.5.8, el análisis siguió un enfoque de métodos complementarios, tanto cualitativos como 
cuantitativos, que buscó triangular y complementar datos discursivos. Para el análisis cualitativo, se realizó un primer análisis descriptivonarrativo que sirve para enmarcar el corpus en su contexto histórico y social. Mediante esta exploración del corpus, se identificaron categorías de análisis pertinentes para el marco teórico y se codificaron colectivamente entre los investigadores. Este proceso, de tipo cíclico y con etapas de auditoría de los resultados correspondientes a cada categoría, implicó la reclasificación y rejerarquización del sistema inicial de categorías a partir de los hallazgos parciales. Posteriormente, se cuantificaron las ocurrencias para cada categoría y subcategoría, resultados con los que se analizaron frecuencias según la fecha de cada discurso.

Para el análisis cuantitativo, se identificaron de forma automática las palabras más frecuentes dentro de grupos de discursos utilizando herramientas de lingüística de corpus (McEnery, Xiao, \& Tono, 2006). No se consideraron ciertas palabras gramaticales y palabras de contenido de alta frecuencia, pero sí otras de relevancia para el análisis, como el uso de pronombres y verbos copulativos conjugados para contrastar persona y número, así como cuantificadores o adverbios de negación. A su vez, se optó en general por trabajar con palabras, y no con lexemas, para poder distinguir entre declinaciones y conjugaciones significativas para el análisis (como las oposiciones "chilenos" /"chilenas", "país" /"países" o "derecho/derechos). Además, se identificaron de forma automática las palabras clave y se calculó su significancia estadística. De forma complementaria, con estas listas simples de frecuencia se rastrearon los contextos discursivos para avanzar en el análisis de colocación, de concordancia y de evaluaciones asociadas, tanto de forma automatizada como contextualizada mediante análisis ad hoc. Cuando resultó pertinente, se normalizaron las ocurrencias (Lukin, 2018) para facilitar la comparación y se indicó la dispersión textual de los fenómenos (es decir, en cuántos discursos distintos se manifestaron).

\section{Resultados y discusión}

\subsection{Discursos y protestas sociales en Chile: un recuento}

Durante el mes previo al estallido social (18/o9-17/10/19), el presidente Sebastián Piñera dio un total de 30 discursos ante distintos públicos domésticos e internacionales, según información oficial de prensa. Los dos 
primeros discursos de la serie tuvieron lugar durante la fiesta nacional de Chile, y lo reflejaron mediante alusiones a la familia y la unidad nacional. Inmediatamente después, Piñera viajó a Nueva York para participar en una serie de eventos como el World Economic Forum y la asamblea general de Naciones Unidas. En todos ellos desplegó un discurso destinado a enfatizar el liderazgo de Chile como nación próspera, democrática y comprometida en la lucha contra el cambio climático y con el multilateralismo como herramienta para superar los conflictos. En contraste, fustigó en varias ocasiones al gobierno de Nicolás Maduro, caracterizándolo como una "dictadura corrupta e incompetente" (22/09/19); el término "dictadura" aparece nueve veces durante este período, siempre asociado a Venezuela.

De regreso a Chile, retomó la agenda doméstica dirigiéndose a públicos heterogéneos como empresarios, pequeños agricultores y adultos mayores. Dominaron este período temas como la sequía que afecta a Chile hace casi una década (la metáfora "terremoto silencioso" es utilizada 10 veces), los incendios forestales y su prevención, las empresas pequeñas y medias (la metáfora "columna vertebral de Chile" es utilizada tres veces), el transporte público, el turismo, los medicamentos y la lucha contra la delincuencia. En estos discursos, Piñera repitió algunos conceptos e ideas fuerza de su gobierno antes del estallido social. Chile fue conceptualizado como "oasis" e "isla" de crecimiento, democracia y prosperidad en América Latina: "veamos nuestro continente, América Latina; Argentina y Paraguay en recesión; los grandes, México y Brasil, estancados; Perú y Ecuador, con grave crisis políticas. Y en medio de ese cuadro está Chile, que emerge como un verdadero oasis. Un país que tiene estabilidad política, que está creciendo, que va a liderar el crecimiento de América Latina" (07/10/19). Además, Piñera se refirió a la necesidad de preservar la unidad nacional ("unamos nuestras fuerzas") y de cuidar lo construido desde el retorno a la democracia ("cuidemos nuestro país", formulación repetida antes y después de las protestas). Para Piñera, "cada generación enfrenta su propio desafío" (frase utilizada con ligeras variaciones 15 veces durante este período) y la suya es luchar contra el cambio climático y lograr que el país se suba a la revolución tecnológica digital, promoviendo el emprendedorismo y la innovación. También introdujo en sus discursos alusiones a Dios y a la Biblia ("por sus obras los reconoceréis").

El viernes 18 de octubre, y luego de una semana de evasiones estudiantiles en el metro de Santiago en protesta por una suba del costo 
del pasaje, comenzó en Chile un estallido social con pocos antecedentes en su historia. Se produjeron cacerolazos y marchas espontáneas en distintos puntos de la ciudad, así como incendios de decenas de estaciones de metro y autobuses. La revuelta social se irradió a todo el país, con manifestaciones y saqueos de supermercados, farmacias y pequeños comercios.

Durante el mes transcurrido después del estallido social, el presidente Piñera pronunció 16 discursos. Muchos de estos discursos, emitidos por cadena nacional, incluían decisiones de gobierno de alto impacto, en particular la decisión de decretar Estado de Emergencia en distintas provincias y comunas y designar un general como "Jefe de la Defensa Nacional" con el propósito de "asegurar el orden público" $(18 / 10 / 19)$. Esta decisión implicó la utilización de personal militar para monitorear las zonas declaradas en emergencia, si bien el discurso presidencial atribuye esta responsabilidad al general a cargo: "frente a esta situación, el general Iturriaga, que está a cargo de este Estado de Emergencia, ha podido disponer de 9500 hombres para resguardar la paz" (20/10/19); la formulación "ha podido disponer" borra en el discurso al responsable último de esa disposición. En algunos de estos discursos, Piñera recicló conceptos y frases del período anterior, como la unidad nacional y las alusiones a la delincuencia, pero desechó otros como el emprendedorismo, la sequía o la innovación tecnológica. Las menciones a Venezuela y el gobierno de Nicolás Maduro desaparecieron por completo, y en su lugar aparecieron frases y temas nuevos vinculados especialmente al actuar de las fuerzas armadas, la violencia y el vandalismo.

A partir del día 25 de octubre comenzó una nueva fase mediante una "agenda social", que en realidad fue un programa destinado a acelerar la tramitación de proyectos de ley ya presentados y a desempolvar otros de su primer mandato. Piñera había "escuchado con humildad" ( $n$ = 2) las "legítimas demandas" ( $n=4)$ de la sociedad. El 29 de octubre reconoció que había víctimas fatales y que se investigarían los eventuales atropellos cometidos por las fuerzas del Estado. Tras anunciar el cambio de su gabinete ministerial y la cancelación de dos grandes eventos internacionales, Piñera bajó el ritmo de sus apariciones públicas. Los discursos restantes oscilaron entre la empatía ("agenda social amplia, profunda y exigente") y el endurecimiento del tono contra "los violentistas" ( $n=4)$, amenazando con nuevas penas y castigos. El 12 de 
noviembre, Piñera anunció lo impensable: cambios a la Constitución elaborada por la dictadura de Pinochet. Finalmente, el 17 de noviembre, tras casi una semana de silencio, traspasó otro umbral al reconocer que "se cometieron abusos". Fue el discurso más empático desde el estallido, y culminó con dos grandes temas de la discursividad de Piñera antes y después del estallido, a saber, el cuidado y Dios: “cuidemos nuestras familias, cuidemos nuestra democracia, cuidemos nuestro maravilloso país. Que Dios bendiga a Chile”. En ese discurso de cierre de la serie, el presidente explicitó este cambio en sus discursos y posiciones de gobierno, asociados a dos opciones que denominó "el camino de la fuerza" y "el camino de la paz": "esta noche optamos por el camino de la razón, para darle una oportunidad a la paz" (17/11/19).

Estas acciones, concesiones y cambios políticos y discursivos fueron concomitantes con otros hechos. El 25 de octubre, 1.2 millones de personas marcharon por el centro de Santiago, de manera simultánea con múltiples marchas en todo Chile. El 11 de noviembre se conoció una encuesta que mostraba que la tasa de aprobación de la gestión de Piñera se había desplomado al 15\%, el índice más bajo en todo su mandato, que un mes antes estaba en el 34\% (CADEM, 04/10/19 y 11/11/19; consultado en cadem.cl). El 14 de noviembre a la madrugada, la mayoría de los partidos políticos de gobierno y de oposición con presencia parlamentaria firmaron el "Acuerdo por la paz social y la nueva Constitución" que convocaría a un plebiscito popular para redactar una nueva Constitución nacional. El 19 de noviembre, parlamentarios de partidos de oposición de izquierda presentaron una acusación constitucional contra el presidente Piñera, con foco en la vulneración de derechos humanos de la ciudadanía durante las manifestaciones. Más importante aún, durante este período se produjeron asesinatos, heridos y detenidos tras el accionar de las fuerzas armadas y policiales. El informe elaborado a un mes de iniciadas las protestas por el Instituto Nacional de Derechos Humanos (INDH) de Chile relevó un total de 6362 detenidos en comisarías (incluidos 759 niños, niñas y adolescentes) y 2391 heridos (de los cuales 222 sufrieron heridas oculares). A su vez, el INDH había presentado, a esa fecha, 384 acciones judiciales (seis por homicidio, siete por homicidio frustrado, 273 por torturas y tratos crueles, 66 por violencia sexual, entre otras) en representación de 544 víctimas (INDH, 18/11/19, consultado en indh. cl). Por su parte, Fiscalía de Chile informó de 19 personas fallecidas 
durante las manifestaciones sociales, dos personas fallecidas bajo custodia del Estado y cinco personas fallecidas por acción de agentes del Estado (Fiscalía, 19/11/19, consultado en twitter.com/fiscaliadechile).

\subsection{Chile y el mundo: discursos presidenciales antes y después del 18 de octubre}

Para ahondar en los contrastes entre los discursos presidenciales en Chile antes y después del 18 de octubre, se elaboró una nube automática de palabras generada con asistencia de software para cada período.

Figura 1. Palabras más frecuentes en discursos presidenciales en Chile (18/09/201917/10/2019). El tamaño de cada ítem léxico da cuenta de su frecuencia relativa (321-28 ocurrencias).

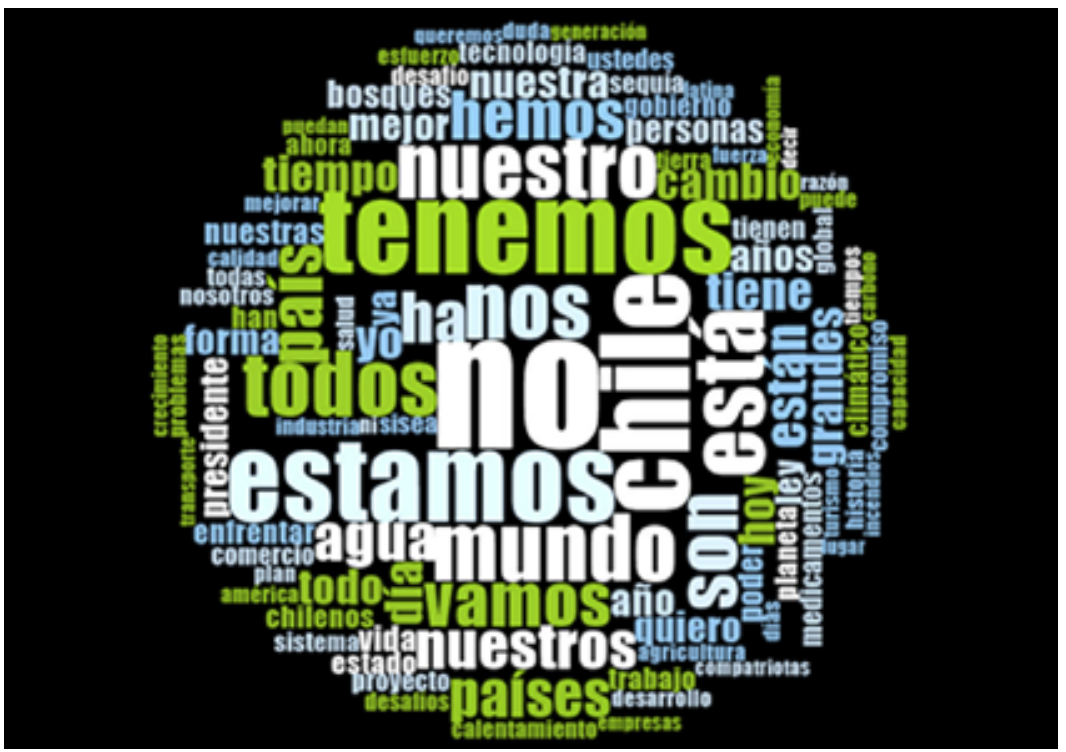

Como puede apreciarse, el discurso presidencial anterior a la protesta social tiene sobre todo un foco internacionalista, con predominancia de las menciones a "Chile" ( $n=227)$ y al "país" $(n=128)$, en general con colocación "mi país", "el país", "nuestro país" o "un país" con ciertos atributos ("sólido", "carbono neutral”, "maravilloso"), junto con el "mundo" ( $n=155)$ y los "países" ( $n=110)$, que combina con Chile adentro ("Chile es de los países que (...)"), así como con Chile fuera ("países como Alemania y Noruega"). Es también un discurso fuertemente dialógico, con el adverbio de negación "no" $(n=321)$ como el ítem léxico más frecuente 
( $0.72 \%$ del corpus). Estas preferencias están naturalmente asociadas a los foros internacionales de enunciación de algunos de esos discursos, pero también, sin dudas, a una predilección temática e ideológica.

A su vez, se evidencia el uso predominante de la primera persona y del conjunto: "tenemos" ( $n=218)$, "estamos" ( $n=208)$, "nos" $(n=157)$, "todos" ( $n=157)$, "nuestro" $(n=152)$, “vamos" $(n=127)$, "hemos" $(n=$ 114), "nuestros" ( $n=109)$, así como la primera persona singular, como en "yo" ( $n=88)$ y "quiero" ( $n=68)$, que colabora con el posicionamiento de autoridad del estadista. En contraste, la tercera persona tiene menor frecuencia, como en "está" ( $n=178)$, "son" ( $n=145)$, "ha" $(n=119) \mathrm{y}$ “están” $(n=96)$.

La frecuencia de palabras de contenido muestra una preocupación por los grandes temas medioambientales, tanto en relación con la -en ese momento- futura Conferencia de las Naciones Unidas sobre Cambio Climático (COP) 25 y las declaraciones de Piñera en Naciones Unidas, como con temáticas locales vinculadas a sequía, incendios y bosques (se colocan entre corchetes las colocaciones más frecuentes): "agua"[potable] $(n=110)$, "bosques"[lluviosos] ( $n=59)$, [nuestro] "planeta"[Tierra] $(n=49)$, [cambio] "climático" ( $n=46)$, [peor] “sequía” ( $n=42)$, “calentamiento"[global] $(n=37)$, [planeta] “Tierra” $(n=36)$, “incendios"[forestales] $(n=30)$. Los discursos presidenciales también se ocupan de ciertos sectores y elementos de la economía: "tecnología" $(n=46)$, “comercio" $(n=41)$, "agricultura" $(n=$ $35)$, “industria” ( $n=33)$ y "turismo" ( $n=32)$; estas últimas dos palabras tienden a aparecer juntas ("industria del turismo"). Al mismo tiempo, ciertas palabras asociadas al discurso del progreso y la expansión económica muestran predominancia: "mejorar" [la calidad] $(n=40)$, "esfuerzo" [enorme, tremendo] ( $n=37)$, “calidad"[de vida] $(n=37)$, [conquistar] "desarrollo" $(n=36)$. Las referencias a los grupos sociales son más bien genéricas, vacías de contenido, en contraste con el uso de "chilenos" ( $n=46)$ y "compatriotas" $(n=29)$ : "personas" $(n=61)$, con colocaciones que van desde "en delito flagrante" hasta "al servicio de"; y "ustedes" ( $n=40)$, usado como vocativo.

El presidente Piñera post protestas sociales cambia drásticamente las palabras y temáticas que articulan su discurso, como se ve en la Figura 2. 
Figura 2. Palabras más frecuentes en discursos presidenciales en Chile (18/1017/11/19). El tamaño de cada ítem léxico da cuenta de su frecuencia relativa (166-14 ocurrencias).

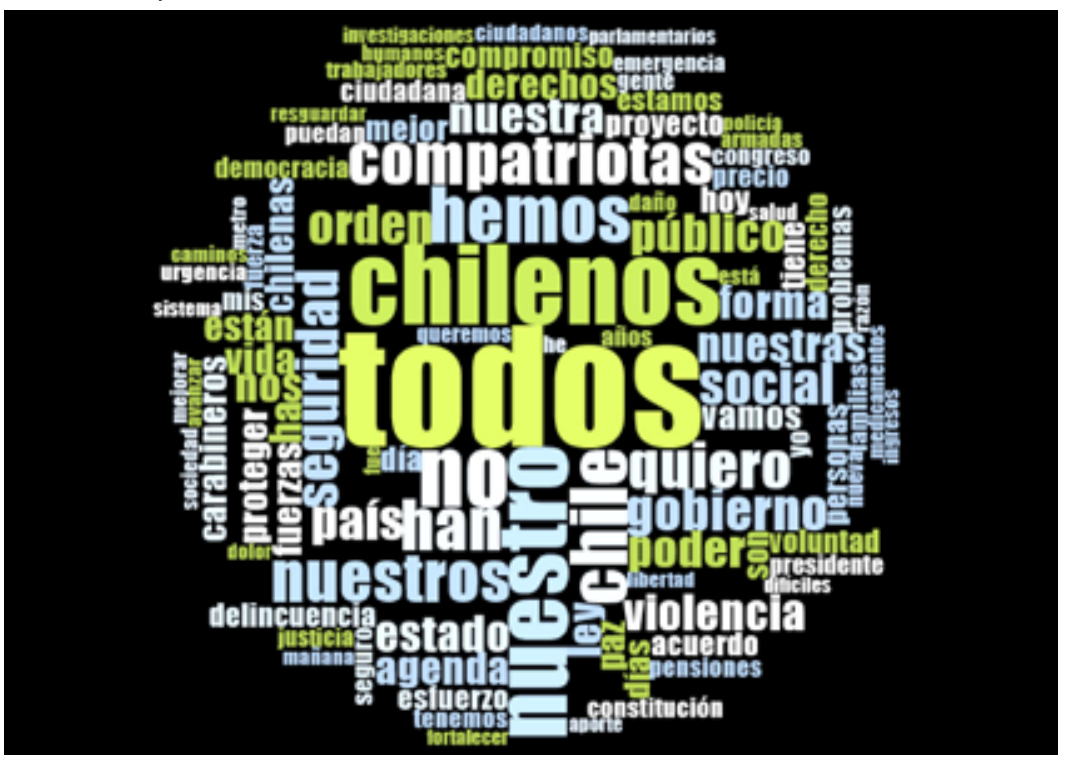

Ahora el foco deja de estar en el mundo y los países, y aterriza exclusivamente en el ámbito local y en los interlocutores connacionales: "chilenos" ( $n=107)$, "Chile" ( $n=76)$, en 12 ocasiones en colocación con "carabineros de Chile”, “compatriotas" $(n=65)$ y "país” $(n=50)$. El mundo prácticamente desaparece del discurso $(n=6)$, así como la locación discursiva pasa a ser exclusivamente local, santiaguina, cuando anteriormente se desplazaba de la capital chilena a regiones, de Perú a Nueva York. Se destaca la caída en la frecuencia relativa del adverbio "no" ( $\mathrm{n}=90)$, un $0.52 \%$ del corpus.

La unidad nacional se torna más enfática con el cuantificador "todos" ( $n=166)$, que coloca con "los chilenos", "los compatriotas", "los hombres y mujeres", "ustedes", al tiempo que continúa la presencia de la primera persona plural con "nuestro" ( $n=94)$, "hemos" $(n=72)$, "nuestros" $(n=64)$. En este sentido, Araya Seguel y Farías Farías (2014) hallaron en un estudio del discurso del presidente Piñera de 2011, frente a las protestas estudiantiles durante su primer mandato, que los términos más frecuentes eran, precisamente, "nuestro" y "todos"; se trata de una misma estrategia de inclusión y consenso frente a la crisis.

En contraste, cae la presencia relativa del pronombre de primera persona singular "yo" $(n=24)$, e irrumpe la tercera persona plural con "han" 
$(n=65)$ asociada a tres polos principales: los delincuentes (colocación "han afectado", "han alterado", "han intentado quemar", "han desatado", "han causado tanto daño"), los manifestantes ("han expresado pacíficamente", "han entregado un mensaje", "nos han transmitido"), y las fuerzas del orden ("han sido heridos", "el compromiso que han demostrado", "han tenido una tarea titánica"). Esta compleja polisemia del otro en la situación de protesta social, con evaluaciones antagónicas asociadas, puede tal vez explicar la dificultad del mandatario para construir y dar continuidad a un discurso de la guerra y el miedo (ver más adelante). Como explica Wodak (2015), un rasgo transversal de los partidos de derecha es la identificación de un grupo minoritario que se construye como peligroso y amenazante al "nosotros" y a "nuestra nación".

En efecto, el discurso de Piñera de este período incluye mención explícita de las fuerzas armadas y policiales frente a la delincuencia, la emergencia y la violencia, construyendo dos polos irreconciliables: "seguridad"[ciudadana] ( $n=55)$, [nuestro] "gobierno" $(n=52)$, "orden" [público] ( $n=49)$, [proyecto de, la Constitución y la] "ley" $(n=42)$, [nuestras] "fuerzas" [armadas] ( $n=34)$, "carabineros" [de Chile] $(n=33)$, "proteger" [la seguridad ciudadana] $(n=34)$, por un lado, y “violencia” $[\mathrm{y}$ la destrucción, y la delincuencia, y el vandalismo] $(n=45)$, [las víctimas de la] "delincuencia" $(n=26)$, [soluciones a los] "problemas" $(n=24)$, [tanto] “daño"[han causado] ( $n=18)$, "urgencia" $(n=18)$, por el otro. El análisis específico de la colocación de "violencia" es interesante, porque muestra su asociación con la delincuencia y el vandalismo, con consecuencias de destrucción, en oposición a la acción de las fuerzas de seguridad del Estado. Como se ha estudiado sobre el discurso de la guerra y la violencia (Lukin, 2018), el discurso presidencial establece una frontera polar entre la fuerza legítima del Estado y sus agentes, que se asocia a la consecución de la "guerra" (ver más abajo), y el accionar perverso e ilegal de los "violentistas" y "delincuentes". Este discurso del miedo se va suavizando y ajustando con el paso de los días. El 22 de octubre, el presidente Piñera comienza a referirse en su discurso a un enemigo más acotado, "pequeños grupos de delincuentes", aunque sigue ajustándose a una misma descripción fuertemente estigmatizada.

El análisis de palabras clave con AntConc confirma el contraste, estadísticamente significativo $(p<.05)$, de elecciones léxicas que cambian el foco del discurso presidencial antes y después del 18 de octubre en las siguientes palabras: "mundo", "países", "agua", "tecnología”, "cambio", 
“sequía”, “bosques”, “tierra”, “agricultura”, “América”, “industria”, "Latina", "turismo", "planeta"; además, el contraste aparece en la primera persona plural de "tenemos" y "estamos" (el contraste en "todos”, "no", "han" y "yo", aunque sugerente, no resulta estadísticamente significativo).

\subsection{Un enemigo poderoso, implacable: el discurso de la guerra}

A pesar de estos fuertes contrastes entre los discursos antes y después del 18 de octubre, hay evidencias de que ciertos rasgos clave del discurso presidencial, y de la ideología que materializa y reproduce, no se modifican sustancialmente al comenzar las revueltas sociales. En efecto, el análisis cualitativo arroja una llamativa continuidad en la selección léxica y en los focos temáticos inmediatamente antes y después del 18 de octubre, como se ve en la Tabla 2 a continuación.

Tabla 2. Referencias a la delincuencia en discursos presidenciales de la semana del 18 de octubre (negrita añadida).

\begin{tabular}{|c|c|c|}
\hline Discurso presidencial & Fecha & Descripción oficial \\
\hline $\begin{array}{l}\text { "Tenemos al frente un enemigo implaca- } \\
\text { ble, formidable, que está en permanente } \\
\text { renovación y evolución, que no respeta a } \\
\text { nada ni a nadie" }\end{array}$ & $\begin{array}{l}15 \text { de } \\
\text { octubre }\end{array}$ & $\begin{array}{l}\text { "Presidente Piñera } \\
\text { participa de Asamblea } \\
\text { General de Interpol" }\end{array}$ \\
\hline $\begin{array}{l}\text { "Al frente tenemos un enemigo podero- } \\
\text { so, implacable, que no respeta a nada } \\
\text { ni a nadie por cumplir sus perversos } \\
\text { objetivos" }\end{array}$ & $\begin{array}{l}16 \text { de } \\
\text { octubre }\end{array}$ & $\begin{array}{l}\text { "Presidente Piñera } \\
\text { encabeza el Desayuno } \\
\text { Anual de la Industria del } \\
\text { Turismo" }\end{array}$ \\
\hline $\begin{array}{l}\text { "La delincuencia es un enemigo formi- } \\
\text { dable, poderoso, cruel, implacable, que } \\
\text { no respeta nada ni a nadie, y tenemos } \\
\text { que combatirlo con toda la fuerza del } \\
\text { mundo" }\end{array}$ & $\begin{array}{l}17 \text { de } \\
\text { octubre }\end{array}$ & $\begin{array}{l}\text { "Presidente Piñera acom- } \\
\text { pañado por la Primera } \\
\text { Dama, Cecilia Morel, } \\
\text { recibe en el Palacio de La } \\
\text { Moneda a los padres de } \\
\text { Baltazar Díaz" }\end{array}$ \\
\hline \multicolumn{3}{|l|}{ (protestas sociales del 18 de octubre) } \\
\hline $\begin{array}{l}\text { "Estamos en guerra contra un enemigo } \\
\text { poderoso, implacable, que no respeta a } \\
\text { nada ni a nadie" }\end{array}$ & $\begin{array}{l}20 \text { de } \\
\text { octubre }\end{array}$ & $\begin{array}{l}\text { "Presidente Piñera da } \\
\text { punto de prensa" }\end{array}$ \\
\hline
\end{tabular}

Como puede apreciarse, en tres días consecutivos previos a las protestas sociales masivas, el presidente Piñera utiliza un mismo discurso del miedo 
y la guerra, articulado con los mismos recursos lingüísticos, aunque multiplicado para distintos públicos, incluida la industria del turismo: la existencia de un enemigo formidable, poderoso, implacable, que no respeta a la población ni a la propiedad, al que hay que combatir. Este enemigo se asocia en el discurso a "la delincuencia, el narcotráfico y el terrorismo" y se le atribuyen rasgos atemorizantes como la sofisticación tecnológica, el armamento de guerra, la creatividad criminal, la acción permanente, el respaldo legal y económico, la adaptación y la maldad absoluta ("está dispuesto a cometer las atrocidades más grandes", 15/10/19). A este enemigo opone un "nosotros", con asociaciones diversas, que debe usar "toda la fuerza del mundo" (17/10/19) para combatirlo en una lucha "sin tregua y sin cuartel" (15/10/19). El discurso de la guerra, como señala Lukin (2018), legitima y normaliza la violencia racionalizada e institucionalizada para un supuesto fin superior de pacificación.

Al culminar esa semana, cuando las protestas sociales habían irrumpido en Chile y se había decretado el Estado de Emergencia, el mandatario reutiliza el mismo discurso en un verdadero copy-and-paste sin solución de continuidad de un solo discurso e ideología: la misma caracterización del otro ("poderoso", "implacable", "que no respeta a nada ni a nadie"), junto con las mismas metáforas bélicas ("enemigo", "combatirlo") y el miedo (al acecho, sin descanso), en el marco de una "guerra".

Para conocer la penetración real del discurso de la guerra y el miedo en la presidencia de Piñera, se realizó una búsqueda simple en un corpus ampliado de discursos presidenciales transcritos ofrecidos por la web oficial de prensa de gobierno. La búsqueda arroja 11 declaraciones similares, como muestra la Tabla 3 a continuación.

Tabla 3. Referencias a la delincuencia en discursos presidenciales en corpus ampliado 11/03/18-17/09/19 (negrita añadida).

\begin{tabular}{|l|l|l|}
\hline Discurso presidencial & Fecha & Descripción oficial \\
\hline $\begin{array}{l}\text { La delincuencia, el narcotráfico y el terroris- } \\
\text { mo son enemigos poderosos, implacables, } \\
\text { crueles y despiadados, que no respetan a } \\
\text { nada ni a nadie para cumplir sus perversos } \\
\text { propósitos }\end{array}$ & 29/03/18 & $\begin{array}{l}\text { Discurso Presidente } \\
\text { Piñera en ceremonia } \\
\text { de Cambio de Mando } \\
\text { de Carabineros }\end{array}$ \\
\hline $\begin{array}{l}\text { Todos los chilenos tenemos que unirnos } \\
\text { frente a un enemigo poderoso e implacable, } \\
\text { que no respeta a nada ni a nadie, y que está } \\
\text { dispuesto a cometer todos los abusos con tal } \\
\text { de conseguir sus perversos objetivos. }\end{array}$ & $07 / 04 / 18$ & $\begin{array}{l}\text { Presidente Piñera } \\
\text { asiste a ceremonia de } \\
\text { entrega de patrullas a } \\
\text { Carabineros }\end{array}$ \\
\hline
\end{tabular}




\begin{tabular}{|c|c|c|}
\hline $\begin{array}{l}\text { Nuestra sociedad está en guerra contra } \\
\text { la delincuencia y el narcotráfico, y todos } \\
\text { sabemos que ésta es una guerra dura y di- } \\
\text { fícil, porque al frente tenemos un enemigo } \\
\text { cruel, implacable y poderoso, que no res- } \\
\text { peta a nada ni a nadie con tal de conseguir } \\
\text { sus perversos objetivos. }\end{array}$ & $11 / 06 / 18$ & $\begin{array}{l}\text { Presidente Piñera } \\
\text { firma proyecto de ley } \\
\text { Anti portonazos }\end{array}$ \\
\hline $\begin{array}{l}\text { Al frente tenemos un enemigo poderoso, } \\
\text { implacable, cruel y que, hoy día, está más } \\
\text { organizado que nunca y que cuenta con } \\
\text { armamento de guerra, y que no respeta a } \\
\text { nada ni a nadie }\end{array}$ & $13 / 06 / 18$ & $\begin{array}{l}\text { Presidente inaugura } \\
\text { Comisaría de San } \\
\text { Bernardo }\end{array}$ \\
\hline $\begin{array}{l}\text { Al frente tenemos enemigos poderosos, } \\
\text { implacables, que no respetan a nada ni a } \\
\text { nadie con tal de conseguir sus perversos } \\
\text { objetivos. }\end{array}$ & $15 / 06 / 18$ & $\begin{array}{l}\text { Presidente inaugura } \\
\text { Quinta Comisaría de } \\
\text { Antofagasta }\end{array}$ \\
\hline $\begin{array}{l}\text { Al frente no tenemos un enemigo débil o } \\
\text { ingenuo, tenemos un enemigo poderoso, } \\
\text { implacable, cruel, que no respeta a nada } \\
\text { ni a nadie con total de cumplir sus perver- } \\
\text { sos objetivos }\end{array}$ & $19 / 06 / 18$ & $\begin{array}{l}\text { Presidente Piñera } \\
\text { asiste a aniversario } \\
\text { de la PDI }\end{array}$ \\
\hline $\begin{array}{l}\text { El terrorismo, que es una pequeña minoría, } \\
\text { que no respeta a nada ni a nadie, que es un } \\
\text { enemigo poderoso, implacable, cruel, que } \\
\text { está dispuesto a todo }\end{array}$ & $28 / 06 / 18$ & $\begin{array}{l}\text { TEMUCO - } \\
\text { Presidente asiste } \\
\text { a presentación de } \\
\text { grupo especial de } \\
\text { Carabineros }\end{array}$ \\
\hline $\begin{array}{l}\text { Al frente tenemos un enemigo formida- } \\
\text { ble, poderoso, cruel e implacable que ha } \\
\text { demostrado que no respeta a nada, ni a } \\
\text { nadie, para cometer sus actos de delin- } \\
\text { cuencia, narcotráfico, crimen organizado o } \\
\text { terrorismo. }\end{array}$ & $07 / 01 / 19$ & $\begin{array}{l}\text { Presidente Piñera } \\
\text { asiste a ceremonia } \\
\text { de asunción del } \\
\text { General Director de } \\
\text { Carabineros }\end{array}$ \\
\hline $\begin{array}{l}\text { Tenemos al frente es un enemigo podero- } \\
\text { so, inteligente, implacable, cruel, que no } \\
\text { trepida ni respeta a nada ni a nadie con tal } \\
\text { de cumplir sus perversos objetivos }\end{array}$ & $21 / 02 / 19$ & $\begin{array}{l}\text { ARAUCANÍA - } \\
\text { Presidente inaugura } \\
\text { comisaría de Lautaro }\end{array}$ \\
\hline $\begin{array}{l}\text { Al frente tenemos un enemigo formidable, } \\
\text { poderoso, implacable, cruel, que no respe- } \\
\text { ta a nada ni a nadie para poder cumplir sus } \\
\text { perversos objetivos. }\end{array}$ & $21 / 05 / 19$ & $\begin{array}{l}\text { IQUIQUE - } \\
\text { Presidente pone en } \\
\text { marcha Comisaría de } \\
\text { Cavancha }\end{array}$ \\
\hline $\begin{array}{l}\text { El narcotráfico y el crimen organizado son } \\
\text { enemigos formidables, son enemigos } \\
\text { poderosos, implacables, crueles que no } \\
\text { respetan a nada ni a nadie }\end{array}$ & $11 / 06 / 19$ & $\begin{array}{l}\text { Presidente Piñera } \\
\text { presenta Comisaría } \\
\text { Virtual }\end{array}$ \\
\hline
\end{tabular}


Tal como puede observarse, durante el año y medio de mandato anterior a las protestas sociales, Piñera utiliza un as de elecciones léxicas calcadas para elaborar un mismo discurso del miedo y la guerra que construye un opuesto entre los ciudadanos de bien y el crimen organizado, enfrentados en una batalla incesante. El 20 de octubre de 2019, a 48 horas del inicio de las protestas sociales masivas, este discurso encontró un nuevo referente, esta vez más masivo y concreto, en el contexto del Estado de Emergencia. Estos hallazgos revelan que no se trata de un exabrupto, sino de un discurso de gobierno que expresa una ideología específica y consistente.

Este discurso del miedo y la guerra no se restringe a esta manifestación formulaica. En efecto, al rastrear los lexemas (incluyendo distintas clases de palabras y declinaciones) "batalla", "combate", "conquista", "derrota” y "lucha" en los discurso presidenciales y codificar cualitativamente la metáfora de la lucha contra la delincuencia, se ve con claridad: para Sebastián Piñera, "la batalla de nuestra vida" es la lucha contra el cambio climático, los incendios, la sequía y el calentamiento global $(n=36)$; al mismo tiempo, se refiere al combate contra el terrorismo, el crimen y la violencia $(n=18)$. Estos dos focos, clima y crimen, se sintetizan en esta frase previa a las protestas sociales, que parece dotar al discurso presidencial de una supuesta épica propia: "ninguna generación, como la nuestra, ha enfrentado desafíos tan grandes, tan trascendentes como, por ejemplo, la lucha contra el cambio climático y el calentamiento global y también la lucha contra el crimen organizado" (15/10/19). Este último uso de la metáfora de la batalla es el que se focaliza en el discurso presidencial después del 18 de octubre: la "batalla que no podemos perder" es, ahora, la batalla contra los "atentados" de la delincuencia $(n=9)$, con solo una mención a la batalla contra el cambio climático al anunciar la no realización de la COP (31/10/2019). Vale aclarar que, junto con estas batallas, el discurso anterior al 18 de octubre también se refiere a "la gran batalla, la madre de todas las batallas" por la educación de calidad $(n=1)$, a las batallas de la independencia de O'Higgins y San Martín $(n=6)$ y al combate contra "el proteccionismo" económico y la pobreza $(n=7)$, que luego del 18 de octubre tendría una aparición aislada, con un sentido nuevo: "lucha para bajar los precios de los medicamentos" (25/10/2019). Hay continuidad, entonces, en la metáfora de la batalla para distintos focos temáticos de interés del gobierno, como muestra la Tabla 4: 
Tabla 4. Objeto de metáfora de la batalla en discurso presidencial pre y post protestas sociales en Chile en frecuencia y porcentaje.

\begin{tabular}{|c|c|c|c|c|c|c|c|c|c|c|c|c|}
\hline & \multicolumn{2}{|c|}{$\begin{array}{c}\text { Cambio } \\
\text { climático }\end{array}$} & \multicolumn{2}{|c|}{ Delincuencia } & \multicolumn{2}{c|}{ Economía } & \multicolumn{2}{|c|}{ Educación } & \multicolumn{2}{|c|}{ Independencia } & \multicolumn{2}{|c|}{ TOTAL } \\
\hline & $n$ & $\%$ & $n$ & $\%$ & $n$ & $\%$ & $n$ & $\%$ & $n$ & $\%$ & $n$ & $\%$ \\
\hline $\begin{array}{c}\text { Pre } \\
18\end{array}$ & 36 & 52.9 & 18 & 26.5 & 7 & 10.3 & 1 & 1.5 & 6 & 8.8 & 68 & 100 \\
\hline $\begin{array}{c}\text { Post } \\
18\end{array}$ & 2 & 16.7 & 9 & 75.0 & 1 & 8.3 & 0 & 0 & 0 & 0 & 12 & 100 \\
\hline
\end{tabular}

Otra novedad que presenta el discurso presidencial es el uso explícito de la palabra "guerra", que genera inmediatas asociaciones intertextuales en el imaginario chileno, en especial con "Chile está en este momento en estado de guerra interna”, según declaró Augusto Pinochet tras el golpe de 1973 y en múltiples ocasiones posteriores (Valdivia Ortiz de Zárate, 2010, p. 167). El presidente Piñera utiliza el término "guerra" 13 veces en 10 discursos previos a las protestas sociales para referirse a la "guerra comercial” o "guerra tarifaria” entre China y Estados Unidos (hay también dos ocurrencias vinculadas a la guerra contra el cambio climático). El discurso presidencial califica esta guerra de "absurda"; no es una guerra en la que quiera participar, sino una guerra que atañe a otros, sobre la que Piñera propone un enfoque racional y de estadista. Sin embargo, cuando el conflicto llega a tierras chilenas el 18 de octubre, estos usos desaparecen por completo. Ahora, Piñera solo apela al ítem léxico "guerra" en un discurso, el del 20 de octubre, y en dos colocaciones que construyen un nosotros (los chilenos) frente a un ellos (los delincuentes) que se enfrentan: "Estamos en guerra contra un enemigo poderoso, implacable" y "ellos están en guerra contra todos los chilenos de buena voluntad".

El estudio del corpus ampliado demuestra que este uso de "guerra", al igual que el resto de las evaluaciones y metáforas del discurso de la guerra y el orden, estaba presente en el discurso previo de Piñera desde el comienzo de su mandato, configurando un verdadero discurso de gobierno: "No solamente nuestro gobierno, [sino] nuestra sociedad está en guerra contra la delincuencia y el narcotráfico. Y todos sabemos que esta es una guerra dura y difícil porque al frente tenemos un enemigo cruel, implacable, poderoso, que no respeta a nada ni a nadie, con tal de conseguir sus perversos objetivos" (11/06/18). De esta forma, Piñera parece querer reciclar un mismo discurso del miedo y la guerra, pero 
para un contexto completamente distinto. Como identifica Žižek (2009) para los discursos del presidente Bush respecto de la guerra de Irak y del colapso bursátil de 2008 en Estados Unidos, son dos versiones de un mismo discurso que evoca una amenaza al estilo de vida nacional y que requiere acciones urgentes y firmes para acabar con el peligro. Es posible que el rechazo social y mediático que causó el uso de "guerra" el 20 de octubre durante el Estado de Emergencia y aplicado al caos social imperante, incluidos los trending topic en Twitter \#PiñeraDictador y \#NoEstamosEnGuerra, haya forzado que su uso se suspendiera desde entonces en los discursos presidenciales: su presencia es nula en los discursos posteriores al 20 de octubre.

En suma, el discurso no es nuevo, sino que lo que cambia es el referente al que se lo imprime. Se trata de una ideología punitiva y atemorizante (Wodak, 2015), aplicada hasta entonces a la delincuencia, el narcotráfico y el terrorismo, pero que se dirige ahora a una situación de caos social que incluye tanto saqueos y barricadas, como marchas, protestas y caceroleos, en el espacio público común. El discurso de guerra legitima la declaración de Estado de Emergencia y el uso del monopolio estatal legítimo de la violencia, incluidas las fuerzas armadas, para reprimir la protesta social. Como plantea Malešević (2010), la guerra no es una aberración o una excepción, sino una constante en la historia de las sociedades humanas, en particular como violencia organizada y burocratizada que busca disciplinar organizaciones sociales complejas, jerárquicas y de gran escala.

\subsection{La guerra y la paz: del derecho a los derechos}

Luego de la masiva marcha de 1.2 millones de personas (25 de octubre) y en el marco de las discusiones parlamentarias por una nueva Constitución (semana del 11 de noviembre), el presidente Piñera comienza a complejizar el discurso del miedo y la guerra, distinguiendo un tercer polo, construido como contrapuesto a la violencia y los delincuentes, a saber, las marchas ciudadanas pacíficas con reclamos justos, como se aprecia en este discurso de transición: "el país y los chilenos hemos vivido tiempos de brutal y destructiva violencia, pero también hemos escuchado el profundo mensaje de la ciudadanía, de las chilenas y chilenos, pidiendo y exigiendo una sociedad más justa y más solidaria" (26/10/19).

Otros cambios son evidentes, como el lugar de la Constitución nacional en los discursos presidenciales. En los 30 discursos previos 
al estallido social, Piñera la menciona solo dos veces, ambas en colocación "la Constitución y la Ley", y para referirse a las fuerzas armadas y policiales: "las Policías y las Fuerzas Armadas tienen por mandato de la Constitución y la Ley el monopolio del uso de la fuerza en las sociedades democráticas" (15/10/19). En cambio, a partir de las revueltas, la Constitución pasa a ocupar un rol predominante: se utiliza 21 veces. Ahora bien, este uso se bifurca: en los discursos de las primeras tres semanas de protestas sociales, hasta el 7 de noviembre inclusive, la Constitución se sigue asociando a la ley y el orden público $(n=10)$, y en particular al aval que otorga al accionar de las fuerzas armadas y policiales: “Tenemos las fuerzas armadas y las fuerzas de orden que están cumpliendo en forma ejemplar la labor que la propia Constitución y la ley les ha encargado" (20/10/19). En cambio, en los discursos del 12 y 17 de noviembre, este uso prácticamente desaparece (solo una ocurrencia) y se asocia a la nueva carta magna acordada por las fuerzas políticas $(n=10)$, con la colocación frecuente “acuerdo por una nueva Constitución”. Este uso de la Constitución en el discurso de Piñera brinda evidencias de que hay dos polos en la serie discursiva posterior a las revueltas sociales: el anterior y el posterior al 12 de noviembre. Las Figuras 3 y 4 expresan, en términos de árbol de palabras, estas dos colocaciones de Constitución: la primera coloca con "Ley”, “otorga”, “instrumentos”, “establecido”, "mandato”, “marco”, “orden democrático", "decretado", "proteger”, "resguardar"; la segunda se asocia a "nueva”, "acuerdo", “Justicia”, "nuestra”, "futura”, "avanzaremos”, “decide”, “lograda”, "garantice”, “elaborada”. Se trata de un mismo ítem léxico que pasa de organizarse alrededor de un discurso del miedo y de la guerra, de lo establecido y mandatado que debe protegerse y resguardarse, a un discurso de acuerdo futuro, en elaboración colectiva, para el avance y el logro. 
Figura 3. Colocación de la palabra "Constitución" en discursos presidenciales 18/10-7/11/2019.

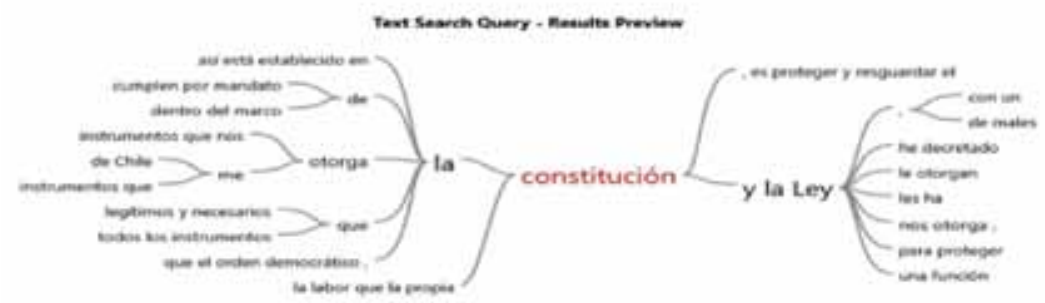

Figura 4. Colocación de la palabra "Constitución" en discursos presidenciales 12-17/11/2019.

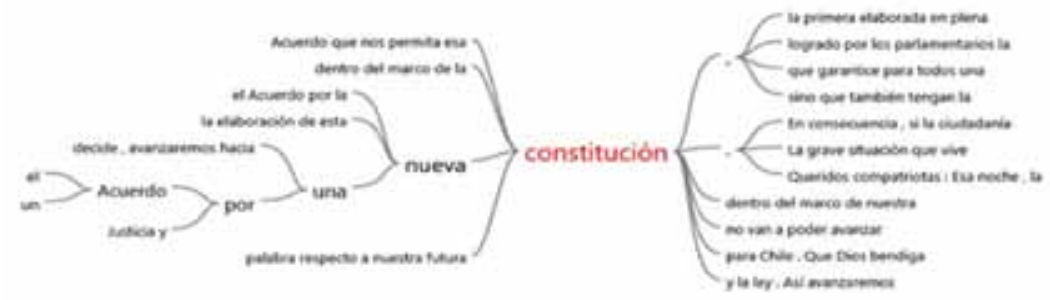

Al profundizar en el análisis de los cambios discursivos durante las revueltas, una de las diferencias más evidentes consiste en la relación entre el gobierno y las fuerzas armadas y de seguridad: tres semanas después de iniciadas las protestas sociales, el discurso presidencial continúa expresando de forma explícita el apoyo al brazo armado del Estado ("Carabineros de Chile y la Policía de Investigaciones cuentan con el total apoyo y respaldo de nuestro gobierno", $n=2$ ), así como cita la Constitución en tanto aval legal de su rol represivo. Pero este apoyo explícito se desvanece en el último discurso presidencial, a un mes de iniciado el conflicto, cuando, aún sin mencionar responsables institucionales mediante un uso excesivo de la voz pasiva ("no se respetaron", "hubo", "se cometieron"), Piñera se refiere por primera vez a la posible persecución legal de casos de violaciones a los derechos humanos, entendidos como "excesos": "en algunos casos no se respetaron los protocolos, hubo uso excesivo de la fuerza, se cometieron abusos o delitos y no se respetaron los derechos de todos. Quiero expresar mi solidaridad y condolencias con las personas que fueron víctimas de esa violencia". Además, pide "condenar en forma categórica y sin ninguna ambigüedad la violencia, la violencia venga de donde venga". De esta forma, la separación entre guerra (violencia legítima 
del Estado) y violencia (delincuencia de los "violentistas") se rompe en un giro infrecuente en el discurso político (Lukin, 2018), quizás debido a que siempre se trató de un uso metafórico de la guerra, a la intertextualidad del término, cara a la memoria histórica chilena, con la dictadura militar, o a la dificultad de distinguir un otro claro al que oponer al "nosotros" nacional.

Estas transiciones entre dos discursos presidenciales, antes y después del 12 de noviembre y su "Acuerdo por la Paz", revelan una construcción discursiva general completamente distinta. En la Tabla siguiente, se muestra el contraste de palabras más frecuentes y clave (hasta seis ocurrencias) entre los discursos del 18 y 20 de octubre ( $n=2403$ palabras) y del 12 y 17 de noviembre $(n=2699$ palabras $)$

Tabla 5. Palabras frecuentes y clave (en negrita) en discursos presidenciales durante las revueltas sociales en Chile.

\begin{tabular}{|l|l|l|l|}
\hline \multicolumn{2}{|c|}{ Discursos del 18 y 20 de octubre } & \multicolumn{2}{c|}{ Discursos del 12 y 17 de noviembre } \\
\hline Todos (26) & Región (8) & Todos (40) & Quiero (9) \\
Compatriotas (22) & Estoy (7) & Chile (21) & Gobierno (8) \\
Hemos (19) & Gobierno (7) & Acuerdo (20) & Social (8) \\
Nuestros (16) & Ley (7) & Chilenos (20) & Avanzar (7) \\
Nuestro (14) & Libertad (7) & Nuestra (14) & Derechos (7) \\
Están (13) & Metro (7) & Nuestro (14) & Seguridad (7) \\
Han (12) & Mis (7) & Violencia (14) & Tenemos (7) \\
Mañana (12) & Orden (7) & Chilenas (12) & Camino (6) \\
Chilenos (10) & Paz (7) & Justicia (12) & Caminos (6) \\
Quiero (10) & Posible (7) & Nuestros (12) & Ciudadanos (6) \\
Chile (8) & Seguridad (7) & Paz (12) & Compatriotas (6) \\
Ciudad (8) & Violencia (7) & Constitución (11) & Compromiso (6) \\
Delincuencia (8) & Democracia (6) & Han (11) & Fuerza (6) \\
Derecho (8) & Emergencia (6) & Hemos (11) & Juntos (6) \\
Fuerzas (8) & Esfuerzo (6) & Nos (11) & País (6) \\
Nuestra (8) & Personas (6) & Familias (9) & Tiene (6) \\
País (8) & Queremos (6) & Nuestras (9) & Voluntad (6) \\
Público (8) & Vida (6) & Nueva (9) & \\
\hline
\end{tabular}

Entre los primeros discursos frente a las protestas y los discursos a un mes de su inicio, la "ciudad" pasa a ser "ciudadanos", palabra que no se utiliza nunca en los primeros discursos; el "derecho" (vinculado a la colocación "estado de derecho" en cinco ocurrencias) pasa a ser 
"derechos" (vinculado a la colocación "derechos humanos" en cuatro ocurrencias); las "fuerzas" (en colocación "fuerzas armadas" y "fuerzas de orden" en siete ocasiones) pasa a ser la "fuerza", en colocaciones diversas que problematizan la violencia: "golpea con fuerza", "camino de la fuerza", "la razón o la fuerza", "uso excesivo de la fuerza", "la sabiduría y la fuerza"; "democracia" es reemplazada por "Constitución" y "justicia” en términos de frecuencia; "personas" cambia por "social", "familias" y "juntos". A su vez, palabras predominantes al comienzo de las revueltas, como "delincuencia", "ley", "libertad", "emergencia” y "orden", pierden su lugar frente a otras como "acuerdo". Otras palabras marcan continuidades entre ambos momentos discursivos: "violencia", "seguridad", "paz". De esta manera, el discurso presidencial coloca el foco en el acuerdo y la justicia, habla de un colectivo social, tanto a nivel ciudadano como familiar, de derechos y de la Constitución, si bien sigue refiriéndose a violencia y seguridad como temas de continuidad discursiva.

Se destaca, además, la aparición de un lenguaje con perspectiva de género: el uso de "chilenas", con una mención en los discursos del 18 y 20 de noviembre (frente a 10 ocurrencias de "chilenos") pasa a tener 12 ocurrencias hacia el final de ese mes (frente a 20 ocurrencias de "chilenos"); su colocación más frecuente es en "chilenas y chilenos" ( $n$ =9), usado como vocativo para referirse a un interlocutor diferenciado. Debido a lo reducido de los corpus comparados, estos contrastes no alcanzan a ser estadísticamente significativos $(p>.05)$, si bien el análisis con AntConc permite identificar las palabras más contrastantes, en el siguiente orden: "mañana", “yo", "ciudad", "región", "compatriotas", "metro", "están", “emergencia”, “queremos", “destruir", "hombres", "Santiago", "abastecimiento", “delincuentes", "normal”, "pido", "precio", "supermercados", "tranquilidad", "mis" “delincuencia”, "batalla”, "defender", entre otras.

Por último, los contextos de enunciación de los discursos presidenciales, su configuración espacial y los actores que participan también dan cuenta de este cambio semántico. El salto de la imagen de la Figura 5 a la Figura 7, correspondientes a los discursos más contrastantes luego del comienzo de las protestas sociales, es también el cambio de una disposición militarizada a otra democrática: del espacio cerrado y claustrofóbico al espacio abierto y en profundidad (asociado al Palacio de la Moneda de la recuperación democrática); de la urgencia de los mapas de contingencia y el micrófono de pie, al agua para beber, el 
micrófono con atril y las columnas estables de la casa de gobierno; del acompañamiento de un ministro en ropa informal y un jefe militar con ropa de combate a la soledad del líder, abrazado y besado por su esposa al culminar su discurso. Entre estos cambios, una imagen de transición (Figura 6): el presidente flanqueado a su derecha por un nuevo ministro del interior y a su izquierda por su nueva vocera, con rostros que simbolizan no solo la renovación formal del gabinete debido a la crisis, sino el recambio generacional y la apertura de Piñera a incorporar figuras ubicadas fuera de su círculo inmediato de confianza (misma familia, grupo social y rango etario).

Figura 5. Fotograma de discurso de Sebastián Piñera del 20/10/2019 (fuente: prensa.presidencia.cl)

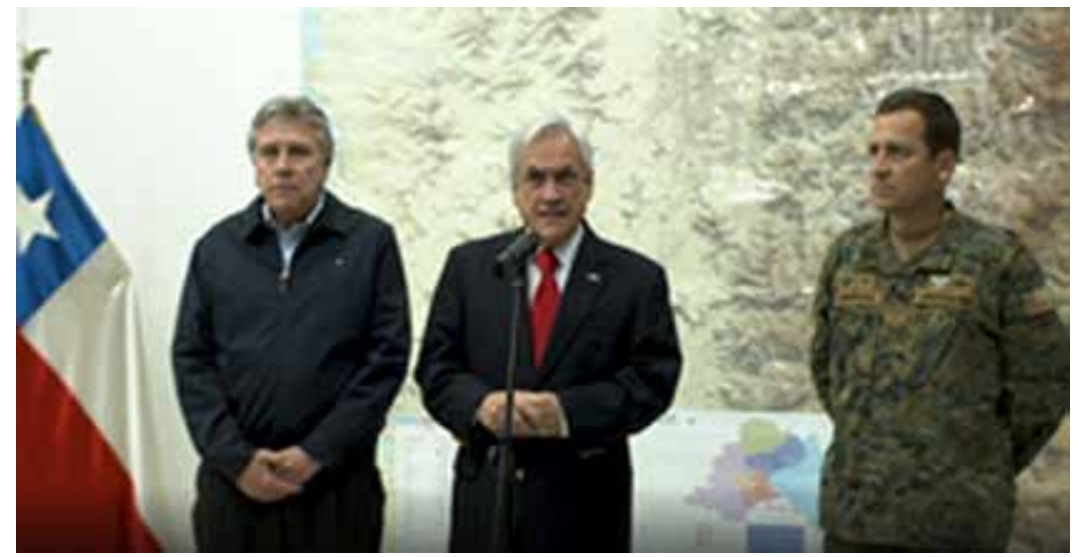

Figura 6. Fotograma de discurso de Sebastián Piñera del 12/11/2019 (fuente: prensa.presidencia.cl)

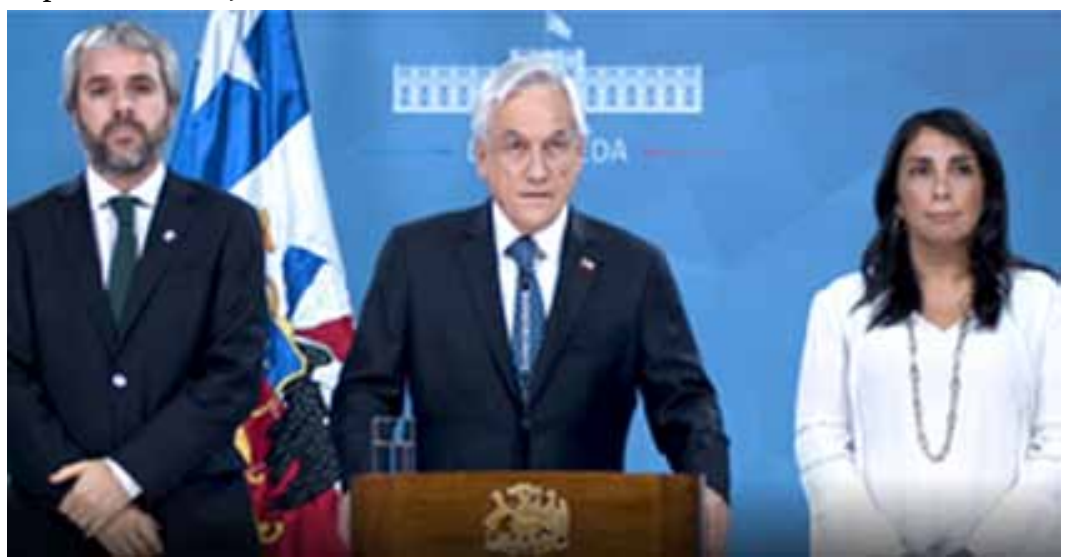


Figura 7. Fotograma de discurso de Sebastián Piñera del 17/11/2019 (fuente: prensa. presidencia.cl)

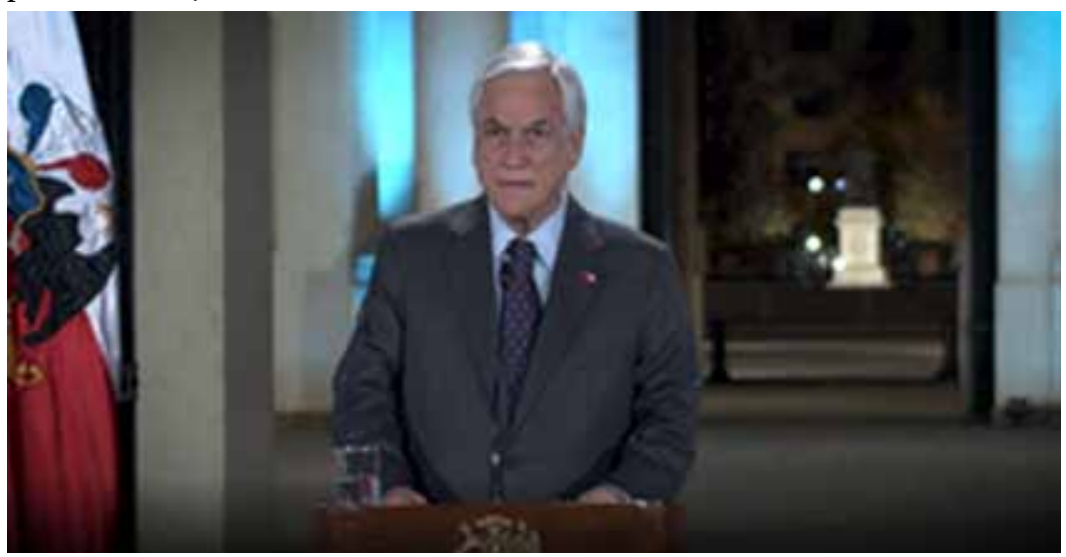

\section{Conclusiones}

Antes del 18 de octubre, Sebastián Piñera reflejaba en sus discursos como presidente de Chile una sensación de autosatisfacción y competencia ante los desafíos. Combinaba el control de la agenda y desplegaba con comodidad una visión de mundo centrada en la eficiencia y la solución de problemas complejos y de largo alcance (cambio climático, terrorismo, situación de Venezuela). Más aún, ofrecía estos discursos ante públicos dóciles o afines en el ámbito internacional, o ante públicos domésticos frente a quienes se presentaba con soluciones concretas y tono de autoridad. De modo general, los 30 discursos de este período están orientados no solo a la audiencia del presente y al ámbito local, sino a públicos del futuro de alcance más allá de las fronteras: el presidente Piñera estaba diseñando su lugar en la historia como un estadista de nivel mundial.

Sin embargo, después del estallido social, cuando la representación de Chile como "un oasis" regional de crecimiento económico y eficiencia dejó de ser sostenible, el discurso de estadista debió ser abandonado del todo. Desapareció el tono tecnocrático, multilateral, liberal y antichavista, centrado en el aprovechamiento de las oportunidades de la revolución tecnológica, el emprendedorismo y la lucha contra el cambio climático.

Los 16 discursos posteriores a la revuelta no solo se hicieron más sucintos y espaciados en el tiempo, sino que tuvieron que realizarse 
a través de cadenas nacionales en las que su auditorio incluía no solo a sus partidarios, sino a públicos escépticos e incluso hostiles. Los recursos retóricos del presidente comenzaron a operar en un contexto de incertidumbre, riesgo y desacuerdo (Fairclough \& Fairclough, 2012). Su primera elección fue dar centralidad al discurso previo de la guerra y el miedo, identificando al "enemigo poderoso e implacable", pero ahora para respaldar la acción represiva de las fuerzas armadas y policiales en el espacio público de protestas sociales masivas. La centralidad que cobró el discurso de la guerra ante la crisis no pudo haber tenido otro objetivo que naturalizar y justificar el uso de la fuerza en toda su dimensión práctica, instalando en el corazón de su discurso una contradicción entre los valores humanistas de su origen socialcristiano y los métodos militaristas heredados de la dictadura militar.

Con el paso de los días y el recrudecimiento de la crisis, Sebastián Piñera y su equipo reconocieron que muchos de sus recursos retóricos se agotaban o no surtían efecto, y se vieron obligados a reemplazarlos por otros. El discurso de la guerra, no como aspiración de consenso ("contra la pobreza" o "contra el cambio climático"), sino como descripción de una nación en crisis, y pronunciado en una puesta en escena militarizada, tuvo que ser retirado paulatinamente y reemplazado por otro centrado en la empatía y el acuerdo, que aceptaba no solo la legitimidad de las protestas, sino el agotamiento del modelo económico y de la propia Constitución que rige Chile desde los tiempos de Augusto Pinochet. Del apoyo irrestricto a la labor de la policía y las fuerzas armadas, el mandatario pasó a un reconocimiento de su labor matizado por la ocurrencia de abusos y excesos cometidos contra la población civil. En ese momento Piñera cruzó una frontera poco traspasada en los discursos de guerra de otros gobiernos: asoció "guerra" (estatal) con “violencia” (criminal) y reconoció el estatus de sus víctimas ("quiero expresarles mi solidaridad").

A diferencia de lo que sostienen muchos de sus detractores, Piñera no tiene un discurso plano: su consistencia y continuidad discursiva, junto con los cambios estratégicos y adaptaciones según la coyuntura, revelan que es consciente de su propia discursividad como creadora de realidad y articuladora de lo político. Supera los alcances del presente trabajo establecer si estas elecciones discursivas constituyen evidencias de responsabilidades ante los delitos cometidos en la represión de las protestas sociales y reconocidos por el propio discurso presidencial. Los 
discursos operan en contextos complejos, dinámicos y multicausales, sus efectos no son mecánicos ni medibles, y el análisis discursivo es, en última instancia, siempre parcial, contingente, subjetivo y discutible. Sin embargo, si, como plantea Fairclough (2003), los discursos tienen consecuencias y efectos sociales, cognitivos, morales y materiales; si el discurso político tiene un rol especialmente clave en situaciones de crisis e inestabilidad; si el discurso presidencial en cadena nacional y multiplicación mediática muestra alcances amplios y profundos desde una posición de asimetría de poder; y si los datos textuales constituyen evidencias empíricas diversas, complementarias y fundamentadas de amplia representatividad; entonces es válido estimar que los discursos analizados en este trabajo cargan con un grado de agencia en los cambios que se han producido en las creencias, identidades, prácticas, cuerpos y bienes de la sociedad chilena desde el 18 de octubre de 2019. Al mismo tiempo, esta responsabilidad interpela el rol que tendrá el presidencialismo reforzado de Chile en las discusiones de expertos en derecho constitucional y representantes ciudadanos en la futura convención constituyente que elaborará una nueva Constitución para el país.

\section{Referencias bibliográficas}

AA.VV. (1986). Análisis sociolingüistico del discurso político. Buenos Aires: UBA.

Araya Seguel, C., \& Farías Farías, M. (2014). El movimiento estudiantil chileno del 2011 en intervenciones discursivas del Presidente Piñera. Logos: Revista de Lingüística, Filosofía y Literatura, 24(1), 51-65. https://doi.org/10.15443/RL2405

Bein, R., Bonnin, J. E., di Stefano, M., Lauria, D., \& Pereira, M. C. (Eds.). (2018). Homenaje a Elvira Arnoux. Tomo VI: Análisis del discurso. Buenos Aires: UBA.

Bolivar, A. (2009). “Democracia” y “revolución” en Venezuela: un análisis crítico del discurso político desde la lingüística de corpus. Oralia, 12, 27-54.

Bronfman Vargas, A. (2016). Presidencialismo y el poder presidencial en el proceso legislativo chileno. Revista Chilena de Derecho, 43(2), 369-400. http://dx.doi.org/10.4067/So718-34372016000200002 
Chilton, P. (2004). Analysing political discourse. Theory and practice. London \& New York: Routledge.

Chilton, P., \& Schäffner, C. (2002). Introduction. Themes and principles in the analysis of political discourse. En P. Chilton \& C. Schäffner (Eds.), Politics as text and talk. Analytic approaches to political discourse (pp. 1-41). Amsterdam \& Philadelphia: John Benjamins.

Fairclough, N. (2003). Analysing discourse: Textual analysis for social research. London \& New York: Routledge.

Fairclough, N., \& Fairclough, I. (2012). Political Discourse Analysis. A method for advanced students. London \& New York: Routledge.

Guerrero S., N., \& Vega A., M. J. (2014). Reflexiones teóricas sobre discurso político e ideología: un análisis preliminar de las políticas de emprendimiento del gobierno de Piñera (Chile 2010-2014). Revista Uruguaya de Ciencia Política, 24(2), 105-120. http:// www.scielo.edu.uy/pdf/rucp/v24nspe/v24nspe06.pdf

Halliday, M. A. K. (2017). Nuevas formas de significar: un desafío para la lingüística aplicada. En E. Ghio, F. Navarro, \& A. Lukin (Eds.), Obras esenciales de M.A.K. Halliday (pp. 139-181). Buenos Aires \& Santa Fe: EUDEBA y UNL.

Ivanova, A. (2015). The topic of education in Chilean political discourse during 2006-2013. Universum, 3o(2), 91-104. http://dx.doi. org/10.4067/So718-23762015000200006

Lukin, A. (2018). War and its ideologies. A social-semiotic theory and description. Singapore: Springer.

Malešević, S. (2010). The sociology of war and violence. Cambridge: CUP.

McEnery, T., Xiao, R., \& Tono, Y. (2006). Corpus-based language studies: An advanced resource book. New York: Routledge.

Munizaga, G. (1983). El discurso público de Pinochet. Un análisis semiológico. Buenos Aires: CLACSO.

Narvaja de Arnoux, E., \& Zaccari, V. (Eds.). (2015). Discurso y política en Sudamérica. Buenos Aires: Biblos

Pérez, S. I. (Ed.) (2014). Análisis del discurso político. Mendoza: UCuyo \& SAEL.

Sclafani, J. (2018). Talking Donald Trump. A sociolinguistic study of style, metadiscourse, and political identity. London \& New York: Routledge. 
Sigal, S., \& Verón, E. (1985). Perón o muerte. Los fundamentos discursivos del fenómeno peronista. Buenos Aires: Legasa.

Slimovich, A. (2017). La ruta digital a la presidencia argentina. Un análisis político e hipermediático de los discursos de Mauricio Macri en las redes sociales. Dixit, 26, 24-43. http://dx.doi. org/10.22235/d.v0i26.1321

Tromben, C. (2016). Crónica secreta de la economía chilena. Santiago: Ediciones B.

Valdivia Ortiz de Zárate, V. (2010). “¡Estamos en guerra, señores!”. El régimen militar de Pinochet y el "pueblo", 1973-1980. Historia, 43(1), 163-201.

van Dijk, T. (1998). What is Political Discourse Analysis? Belgian Journal of Linguistics, 11, 11-52. https://doi.org/10.1075/bjl.11.03dij

Wodak, R. (2015). The politics offear. What right-wing populist discourses mean. Los Angeles: SAGE.

Žižek, S. (2009). First as tragedy, then as farce. London \& New York: Verso. 